\title{
Stem cells: science, policy, and ethics
}

\author{
Gerald D. Fischbach ${ }^{1}$ and Ruth L. Fischbach ${ }^{2}$ \\ ${ }^{1}$ Faculty of Medicine and ${ }^{2}$ Center for Bioethics and Department of Psychiatry, \\ Columbia University College of Physicians and Surgeons, New York, New York, USA.
}

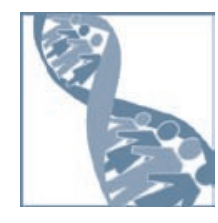

\begin{abstract}
Human embryonic stem cells offer the promise of a new regenerative medicine in which damaged adult cells can be replaced with new cells. Research is needed to determine the most viable stem cell lines and reliable ways to promote the differentiation of pluripotent stem cells into specific cell types (neurons, muscle cells, etc.). To create new cell lines, it is necessary to destroy preimplantation blastocysts. This has led to an intense debate that threatens to limit embryonic stem cell research. The profound ethical issues raised call for informed, dispassionate debate.
\end{abstract}

\section{The promise of stem cell research}

Few subjects in biomedical science have captured the imagination of both the scientific community and the public as has the use of stem cells for the repair of damaged tissues. Because they may be able to replace cells that have atrophied or have been lost entirely, stem cells offer the hope of restoration of cellular function and relief from suffering associated with many disabling disorders. Beyond tissue repair, cultured stem cells might also find application in the analyses of disease mechanisms and normal development, as assays for screening new drugs, and as vehicles for gene therapy (1).

Each potential use of stem cells promises revolutionary advances. However, the word "promise" must be underscored - to date, no cures have been realized, no disease mechanisms have been uncovered, and no new drugs have been developed. Many in the international scientific community believe that the promise of stem cell-based studies or therapies will be realized only if we can derive new human embryonic stem cell (hESC) lines.

At the present time, the production of new cell lines involves destruction of preimplantation embryos at the 100-200 cell (blastocyst) stage. Debate currently centers on the moral status of these embryos, which are now stored at in vitro fertilization (IVF) clinics or created by somatic cell nuclear transfer (SCNT; discussed in detail below). What is the moral status of the blastocyst? Should blastocysts be protected under the same laws that govern research on human subjects? These and related questions are at the center of a debate that involves the lay public, the scientific community, the press, and the United States Congress.

The outcome of this debate will have an impact on the way we conduct the science of hESCs, a field still very much in its infancy. Indeed, the integrity of the scientific process and its independence from politics and from fundamentalist dogma are at stake. It is important, therefore, to define the relevant terminology and discuss it objectively. Along the way we must reduce the emotional valence of phrases such as "therapeutic cloning" and "destruction of embryos." To engage in this debate, it is important to have an overview of stem cell biology.

This article is adapted from a lecture delivered to the faculty and staff of Columbia University Medical Center on September 23, 2003, by Gerald D. Fischbach at the invitation of Ruth L. Fischbach.

Nonstandard abbreviations used: hESC, human embryonic stem cell; ICM, inner cell mass; IVF, in vitro fertilization; SCNT, somatic cell nuclear transfer.

Conflict of interest: The authors have declared that no conflict of interest exists.

Citation for this article: J. Clin. Invest. 114:1364-1370 (2004).

doi:10.1172/JCI200423549.

\section{Stem cells defined}

A stem cell is defined by two properties (see A stem cell research lexicon). First, it is a cell that can divide indefinitely, producing a population of identical offspring. Second, stem cells can, on cue, undergo an asymmetric division to produce two dissimilar daughter cells. One is identical to the parent and continues to contribute to the original stem cell line. The other varies in some way. This cell contains a different set of genetic instructions (resulting in an alternative pattern of gene expression) and is characterized by a reduced proliferative capacity and more restricted developmental potential than its parent. Eventually a stem cell becomes known as a "progenitor" or "precursor" cell, committed to producing one or a few terminally differentiated cells such as neurons or muscle cells.

The different types of stem cell populations can be illustrated by considering the earliest stages of embryogenesis (Figure 1). Soon after fertilization, the haploid nuclei of the egg and sperm merge to form a single nucleus with the diploid number of chromosomes. The zygote divides and its progeny also divide several times thereafter to form a compact ball of cells called the morula (likened in appearance to a mulberry). Each of the $32-128$ cells in the morula is totipotent in that each one can give rise to all cell types in the embryo plus all of the extraembryonic tissues necessary for implantation in the uterine wall. These cells are also at the center of preimplantation genetic testing (see Totipotent cells and genetic testing).

As the morula is swept along the oviduct, the cells continue to proliferate and the morula enlarges to form a hollow sphere called a blastocyst (or blastula). During the final days in the oviduct and the first days in the uterus, a few cells delaminate from the surface layer of the blastula to form an inner cell mass (ICM) within the cavity. This cluster of cells is the source of embryonic stem cells. It is important to emphasize that the ICM forms prior to implantation. Blastocysts created in vitro contain an ICM even though the embryo was created and maintained in a test tube. It is possible to isolate cells from the ICM of human blastocysts and grow them in tissue culture (Figure 2), using techniques first developed 20 years ago for the manipulation of mouse embryos. Cells dissociated from the ICM are pluripotent in that they can become any of the hundreds of cell types in the adult body. They are not totipotent because they do not contribute to extraembryonic membranes or the formation of the placenta.

The time from fertilization to implantation in the uterine wall is approximately 14 days in humans. Soon after implantation, the blastocyst invaginates, much like a finger pressing into a round rubber balloon. A critical series of cell movements known as gastrulation results in the formation of the three germ layers of the 

A stem cell research lexicon
Cell line
Cloned cell line
Stem cell
Zygote
Morula
Blastocyst (or blastula)
Progenitor (or precursor) cell
Totipotent cell
Pluripotent cell
Multipotent cell
Homogeneous population of cells capable of self renewal
Population of cells that derives from replication of a single cell
Cell that can divide indefinitely to produce a population of identical offspring
Diploid cell resulting from the fusion of male and female gametes at fertilization
Spheroidal mass of cells resulting from early cleavage divisions of the zygote
4-5 day-old embryo formed prior to implantation in the uterus; consists of a hollow mass
of only a few undifferentiated stem cells
Parent cell that is committed to dividing and multiplying in order to produce
a specific cell type
Cell committed to a specific lineage that is capable of giving rise to all types of differentiated cells and tissues, including extraembryonic tissues
Cell not committed to a specific lineage that may differentiate into all types of cells and tissues, with the exception of extraembryonic tissues
Progenitor cell that can give rise to diverse cell types in response to appropriate environmental cues

developing embryo: the ectoderm, the endoderm, and the mesoderm. The basic plan of the human body is laid out during this remarkable process as the fate of many cells is determined: the endoderm gives rise to the vasculature and blood-forming organs; the mesoderm produces muscle; and the ectoderm gives rise to the skin and the nervous system.

Stem cells are present in each of the three germ layers. The spectrum of offspring from these stem cells is more restricted than that of cells derived from the ICM, so they are described as multipotent rather than pluripotent. Cells in one germ layer breed true; they do not ordinarily transdifferentiate to form derivatives of other germ layers. Indeed, there is strong evidence for a restriction of developmental potential with time throughout embryogenesis $(2,3)$. However, the plasticity of adult stem cells is an issue of great interest, and it merits further investigation.

\section{Stem cells in adult tissues}

Stem cells have been identified in adult tissues including skin, intestine, liver, brain, and bone marrow. Bone marrow stem cells have been studied most extensively because a variety of cell surface and genetic markers have helped delineate various stages of their differentiation during hematopoiesis.

But there are several drawbacks that, a priori, make adult stem cells less attractive than embryonic stem cells as sources for most of the uses described above. It has been difficult to isolate stem cells from adult tissues. The cells are few in number, and it is difficult to keep them proliferating in culture. To date, it appears that cultured adult stem cells give rise to only a limited number of cell types. Finally, they are adult cells and have been exposed to a lifetime of environmental toxins and have also accumulated a lifetime of genetic mutations.

Despite these apparent drawbacks, research on adult stem cells should be pursued vigorously because these problems may be overcome with new techniques and insights. The therapeutic value of partially purified hematopoietic stem cells in repopulating the bone marrow following high-dose chemotherapy is based on the discovery of growth factors that promote the multiplication of blood precursor cells. We need the same type of information about the differentiation of other types of adult stem cells.

\section{Embryonic stem cells}

The ability of hESCs to proliferate indefinitely in tissue culture and the wide range of cell types to which they give rise make these cells unique. They become even more valuable as new molecules that trigger their differentiation in vivo are discovered. It has proven easier to mimic the normal sequence of development than to reverse this process in an attempt to have cells dedifferentiate.

In 1998, capitalizing on nearly twenty years of experience with mouse embryonic stem cells, scientists at the University of Wisconsin isolated stem cells from the ICM of human blastocysts

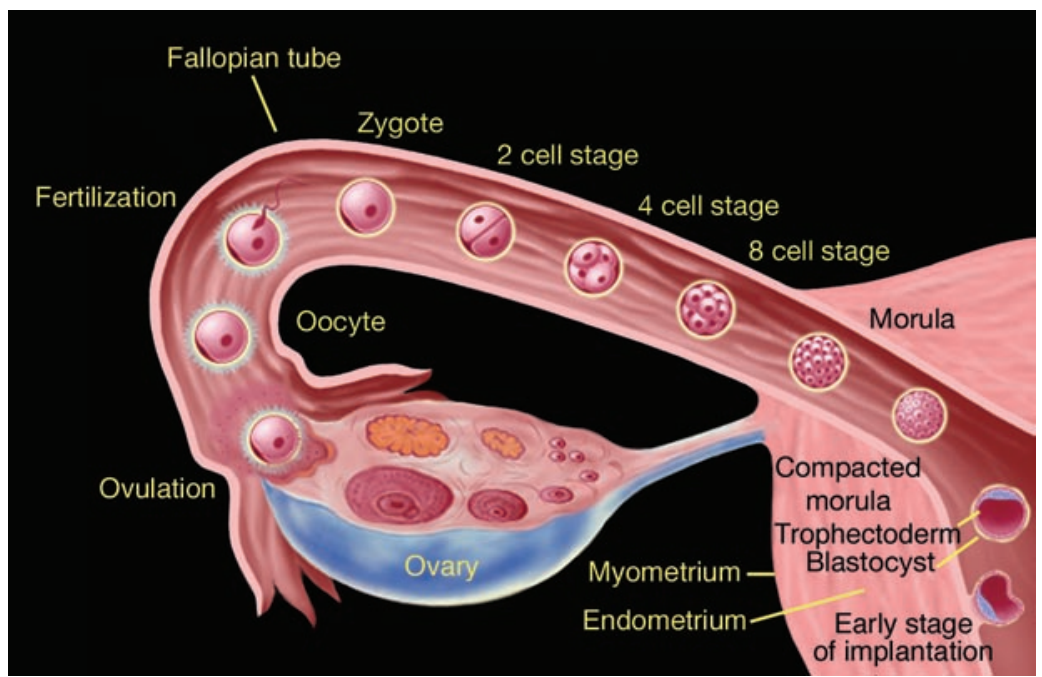

Figure 1

From zygote to blastula: the early stages of human development. Shortly after fertilization, the zygote repeatedly divides to form a solid mass of cells known as the morula. Two to three days after fertilization, the morula enters into the uterine cavity and forms a hollow sphere: the blastocyst. The surface cells form the trophoblast and give rise to extraembryonic tissues, while the inner cell mass is the source of embryonic stem cells and ultimately gives rise to the embryo, following implantation in the uterine wall. 


\section{Totipotent cells and genetic testing}

The fact that each cell within the morula is totipotent means that one or more cells can be sacrificed without harm. This has led to the remarkable new technique of preimplantation genetic diagnosis, in which one of the morula cells is drawn into a micropipette and subjected to a sensitive PCR assay using cDNA primers now available for an increasing number of genetic disorders in order to screen for potential diseaseassociated mutations. This remarkable technology allows physicians to inform parents of the health of the embryo before implantation of the still-viable morula in the uterus.

and grew them in tissue culture for prolonged periods of time (4). Under the right conditions, several types of mature cells appeared in the cultures, including nerve cells, muscle cells, bone cells, and pancreatic islet cells (Figure 2). This paper has led to an explosion of research on hESCs.

Results obtained from studies with mouse ESCs raise the possibility that clinical trials with hESCs are not far off. Mouse ESCs have been steered to become spinal cord motor neurons (5), dopaminergic neurons $(6,7)$, and many other types of cells. One example must suffice here to emphasize their therapeutic promise. In one of the most thorough and elegant studies published to date, mouse ESCs were steered to differentiate into spinal cord motor neurons by successive exposure to retinoic acid and sonic hedgehog, a protein known to trigger the differentiation of motor neurons in developing embryos (5). When treated cells were injected into the spinal cord of a chick embryo, they migrated to their proper location in the ventral horn. Some cells sent axons out of the spinal cord to invade the developing limb (Figure 3) and form synapses on target muscle fibers. This type of research lends hope to individuals suffering from amyotrophic lateral sclerosis, spinal muscular atrophy, spinal cord injury, and related disorders.

Another argument for support of stem cell research follows from the success of transplanting intact human tissues. Pancreatic islets have been implanted into patients with type 1 diabetes to restore them to insulin independence (8). Islet transplantation, according to the Edmonton protocol, works $(9,10)$. Likewise, implantation of fetal mesencephalic brain tissue into the brains of patients with Parkinson disease resulted in measurable improvement in some indices of motor performance (11). Both implantation studies, however, were limited by tissue availability and, in the Parkinson disease study, there were serious side effects (e.g., dyskinesias). Both studies call for further work with hESCs, with the hope of moving to Phase 1 clinical trials.

There is much to learn regarding the use of stem cells for the treatment of disease. We need additional information about how to keep ESCs dividing until they are called on to differentiate. We must learn more about the growth factors that influence their differentiation into diverse cell types. Most importantly, we must endeavor to devise stem cell therapy protocols that are safe. This will be greatly facilitated by our understanding of how to turn these cells off in vivo in the event that toxicity develops. In addition, the risk of immune rejection remains a problem. Given the limited genetic diversity of available cell lines, transplantation of stem cell products is subject to the same immune barriers as organ transplantation. At the present time, our only defense against rejection is the administration of long-term immunosuppression therapy, which increases the patients' risk of infection and is associated with nephrotoxicity. In the future, immune rejection might be minimized without the need for toxic drugs, using cells obtained from blastulae that have been created by SCNT.

\section{Somatic cell nuclear transfer}

In SCNT, the nucleus from a mature cell is injected into the cytoplasm of an oocyte from which the original (haploid) nucleus has been removed. As in the union of haploid sperm and egg nuclei, one ends up with a diploid number of chromosomes, but in the case of SCNT, all of the chromosomes originate from the donor nucleus. The great advantage of SCNT is that the ESCs derived from blastocysts so created will be genetically similar to the cells of the individual who donated the nucleus. It is less likely, therefore, that the expressed proteins will be recognized as foreign and evoke an immune response in the host (12).

It is difficult to reproduce the course of early embryonic development by reprogramming an adult nucleus. Factors in the egg cytoplasm that regulate gene expression in the hours after a zygote is formed must act in the adult nucleus to produce the same patterns of gene activation that are critical for early embryonic development. The striking success of Korean investigators in deriving new hESC lines from embryos created by SCNT has been widely noted (13-15).

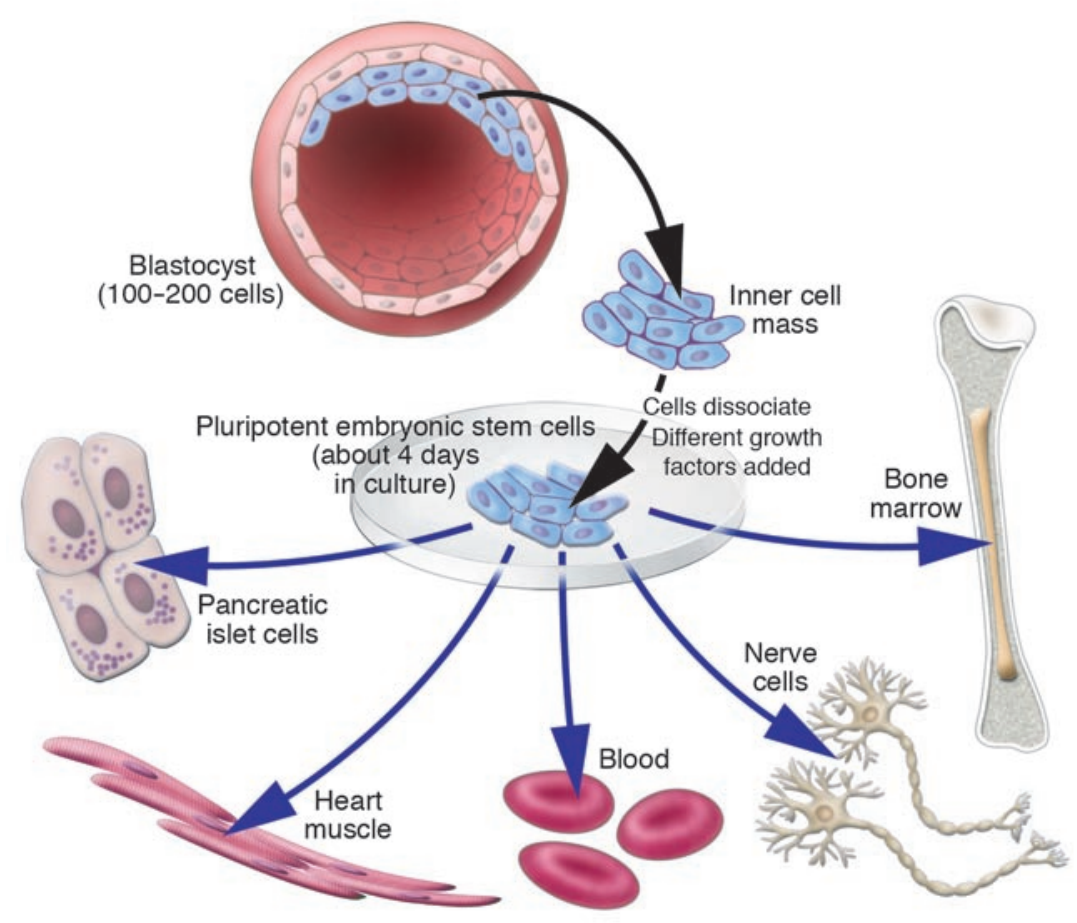

Figure 2

Pluripotent stem cells, isolated from the ICM in the blastocyst, have the ability to give rise to all types of cells in the human body, but not the placenta and other supporting tissues. 


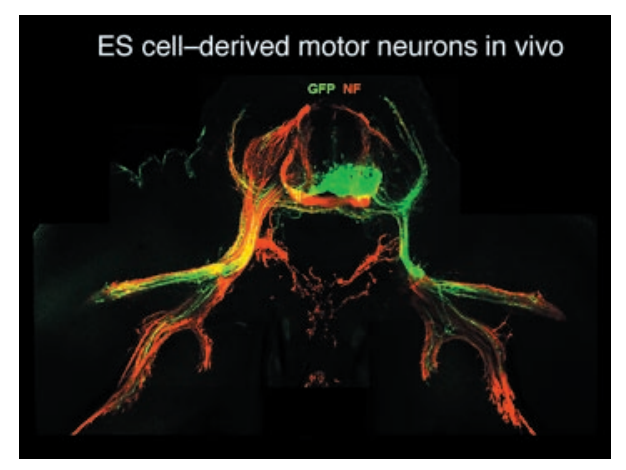

Figure 3

Integration of transplanted mouse embryonic cell-derived motor neurons into the spinal cord in vivo. Transverse section through the lumbar region of the spinal cord reveals that enhanced GFP+ axons exit the spinal cord via the ventral root and project along nerve branches that supply dorsal and ventral limb muscles. The pathway of axons is detected by neurofilament (NF) expression. Reprinted with permission from Cell Press (5).

These ESCs may not be entirely "normal," in the sense that subsequent coordinated development is impaired, but they can serve as starting points for the production of specific cell types.

The use of SCNT for the purposes of creating stem cell lines seems to be an innocuous process, but intrauterine implantation of blastocysts created by SCNT might lead to a live birth, a process known as reproductive cloning (Figure 4). Dolly the sheep was generated using this technology. However, successful reproductive cloning is an extremely improbable event. Most embryos created by SCNT are malformed and die in utero. It required 277 attempts to create Dolly, and there is strong evidence that Dolly exhibited many pathologies (e.g., arthritis, obesity) throughout her life (16-18). No one knows how many attempts it would take to create a live human being or what genetic abnormalities such an individual would bear (19-22).

Mice have been cloned from adult nuclei, even from postmitotic, terminally differentiated olfactory neurons (23). Although the full diversity of olfactory neurons was present in the offspring, more work is needed to define the limits of normalcy in such animals.

Years of experience with animals makes it clear that attempts at reproductive cloning of humans is scientifically unjustifiable at this time. Moreover, there are no compelling medical reasons to pursue this research. "Cloning" means to copy, and the word evokes an image of an identical replica. Given all of the epigenetic events that must occur during differentiation, it is inconceivable that an exact replica of an individual animal let alone a human being can be made. Parents of identical twins easily recognize the enormous number of differences between them.

The terms "research cloning" and "therapeutic cloning" have been applied to the creation of blastocysts by SCNT. These terms are unfortunate as they have become confused in the public's mind with reproductive cloning. They share a common word, and they (wrongly) evoke the worst connotations of the oversimplified image of cloning.

\section{Current regulations}

At the present time, no research on human embryos, including preimplantation blastocysts, can be supported with federal funds. Researchers must perform such studies with the aid of funding obtained from businesses, private foundations, or other philanthropic sources. This ban includes embryos stored frozen in IVF clinics and embryos created by SCNT. It sets us apart from many countries throughout the world.

The Code of Federal Regulations (CFR) is a collection of regulations issued by agencies of the federal government. Title 45 of the CFR covers the Department of Health and Human Services (DHHS). Part 46 - Protection of Human Subjects - of Title 45 covers research on human subjects and mandates the review of federally funded research involving human subjects by an institutional review board. The regulations originated in 1981 following revelations regarding the Tuskegee Syphilis Trial (1932-1972) in which a group of 400 indigent, black Americans, exploited and prevented from receiving penicillin during the 1940s, 1950s, and 1960s, were allowed to undergo the ravages of tertiary syphilis during the length of the trial. The study prompted the US Congress to establish the National Commission for the Protection of Human Subjects of Biomedical and Behavioral Research. The Commission was asked to develop the basic ethical principles that should govern research using human subjects. The result was the Belmont Report (24), one of the most influential documents in the field of bioethics since it defined the basic ethical principles relevant to research involving human subjects: the principles of respect for persons (autonomy), beneficence, and justice. The protections of 45CFR46 became known as the Common Rule after adoption in 1991 by all federal agencies conducting research with human subjects. Subpart A deals with the basic policies for human subjects protection. Subpart B (now called Additional Protection for Pregnant Women, Human Fetuses, and Neonates Involved in Research) relates to research on viable fetuses, pregnant women, and human IVF. Subpart C pertains to studies involving prisoners, while Subpart D describes special requirements for experiments involving children.

In Subpart B, protections are extended to "the product of conception from implantation until delivery." Recall that the ICM of the blastocyst is formed prior to implantation, which occurs on about day 14 after fertilization. Therefore, dissociation of the ICM is legal according to 45CFR46.

In 1996, Representatives Jay Dickey (R-AR) and Roger Wicker (R-MS) introduced an amendment to the DHHS Appropriations Bill (the source of NIH funds) that overrides Subpart B of 45CFR46 by extending protection to "any organism not protected as a human subject under 45CFR46 that is derived by fertilization, parthenogenesis, cloning, or any other means from one or more human gametes or diploid cells." The Dickey Amendment includes "research in which a human embryo is destroyed, discarded, or knowingly subjected to risk of injury or death greater than that allowed for research on fetuses in utero.” Thus, preimplantation blastulae are included in the Dickey Amendment. Dissociation of the ICM necessarily destroys the blastocyst and hence, places it above minimal risk. This amendment is attached to the Appropriations Bill each year. Both President Clinton and President George W. Bush have signed bills containing the language of the Dickey Amendment. This amendment blocks investigators in the United States from using federal funds to derive new stem cell lines from early embryos.

In early 2000, Harriet Raab, then General Council of the DHHS, adopted the view that stem cells are not organisms (embryos) and hence are not covered by 45CFR46 or by the Dickey Amendment. Research on hESCs could, therefore, be supported by government funds, provided that the cells were derived from embryos using private funds. This opinion was adopted by Harold Varmus, then- 
A

Normal Development

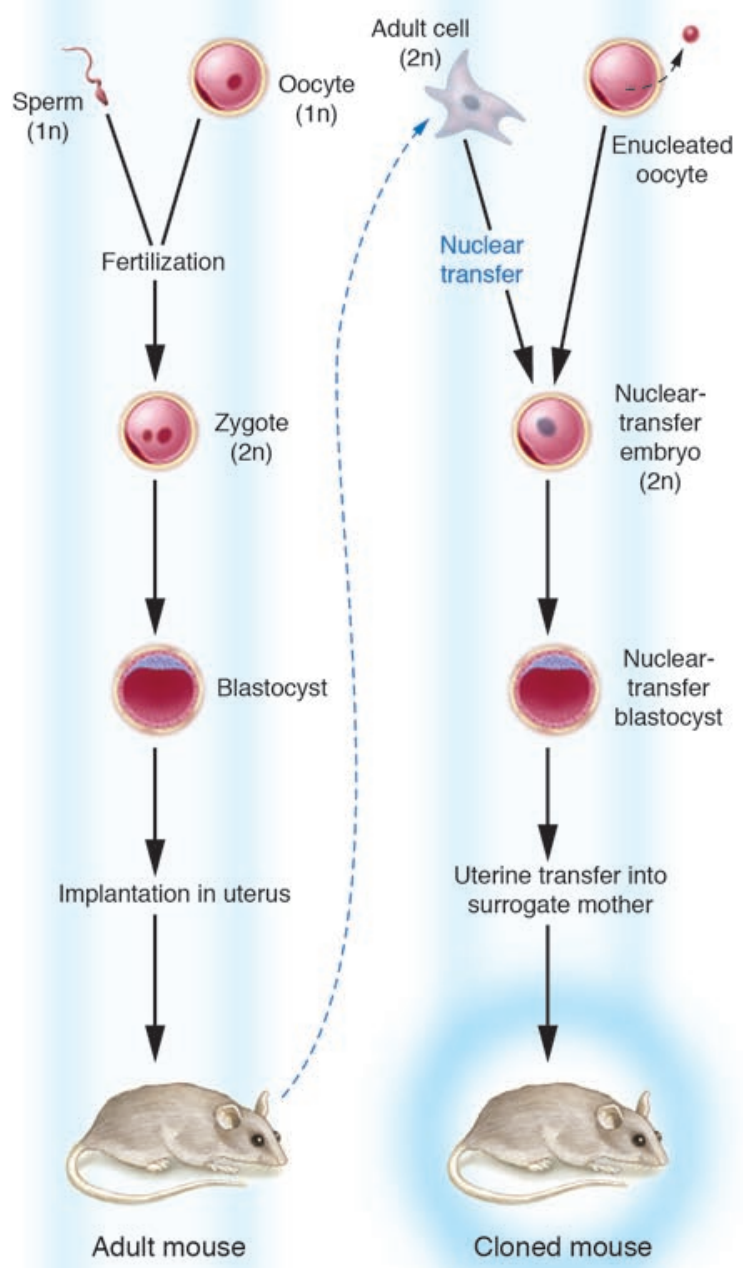

B

Reproductive cloning

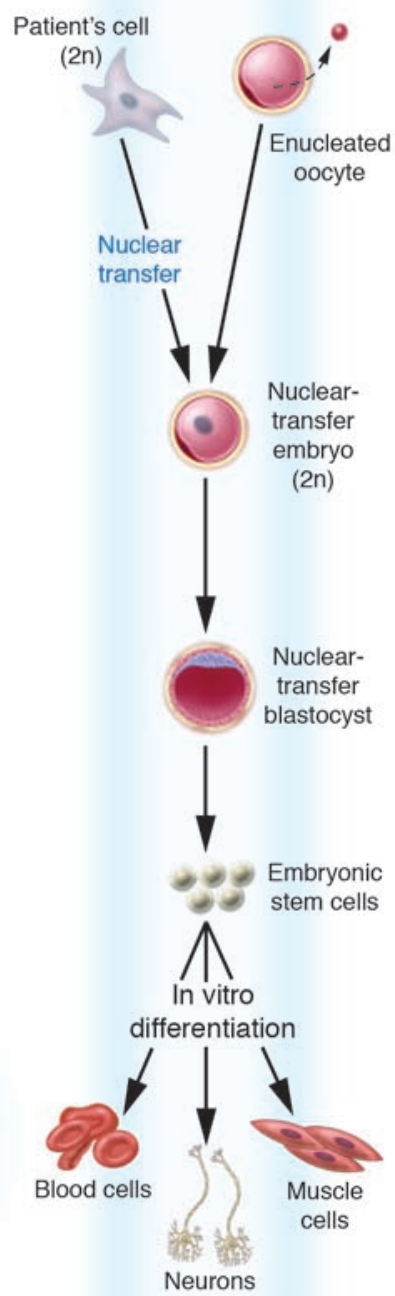

\section{Figure 4}

Normal development versus development during reproductive cloning and therapeutic cloning. During normal development (A), after fertilization, a diploid zygote is formed, which then undergoes cleavage to form a blastocyst that may be implanted in the uterus and result in a live birth. During reproductive cloning (B), the diploid nucleus of an adult donor cell is introduced into the enucleated oocyte. Following artificial activation, division results in a cloned blastocyst. Upon transfer into a surrogate mother, a small number of cloned blastocysts give rise to a clone. Therapeutic cloning (C) requires the explantation of cloned blastocysts in culture to yield an ESC line able to differentiate in vitro into any type of cell for therapeutic purposes. Figure modified with permission from the New England Journal of Medicine (31).

Director of the NIH, but it caused an uproar in Congress as many members felt that the Raab opinion was a legalism that violated the spirit of the law. Nevertheless, the NIH formed a committee of scientists, lawyers, patient advocates, and clergy to consider guidelines for the use of hESCs. They labored for many months. The final document stated that an NIH grantee could use these hESCs provided several criteria were met, including the following: (a) the stem cells were derived from embryos produced in IVF clinics for reproductive purposes; (b) the stem cells were in excess of clinical need, meaning that the donors had achieved a successful pregnancy or had simply decided not to proceed with IVF; (c) the stem cells were derived from embryos that were frozen, allowing sufficient time between the emotional experience of creating the embryos and the decision regarding donation; (d) informed consent and institutional review board approval was obtained; and (e) no exchange of money was made, in order to avoid a financial influence.

As of March 2004, there were more than 400,000 frozen embryos stored in IVF clinics nationwide. The options open to donors of these embryos are to destroy them, offer them up for adoption, continue to store them, or donate them for medical research.

These NIH guidelines were accepted by President Clinton but rejected by President George W. Bush soon thereafter. In his speech of August 9, 2001, President Bush recognized the value of research on hESCs and the promise of successful cell replacement therapies. However, he said that he would not condone the destruction of additional embryos to create new hESC lines. At the time, he believed that $62 \mathrm{hESC}$ lines were available in labs around the world, and he made it clear that all subsequent federally supported research would be confined to these existing lines.

Reaction in the scientific community was mixed. Some were relieved that the President recognized the importance of hESC research. Other investigators, skeptical about the existence of 62 cell lines, were disappointed. In the following months it became obvious that there were not 62 usable cell lines; there were fewer than 5 . The number of available lines has since grown, and 21 lines are currently listed in the NIH registry (25). However, the tangle of intellectual property requirements and the fact that most of these hESC lines were cultured in contact with mouse cells and bovine serum limits their utility. Moreover, many of them still have not been well characterized in terms of viability and their ability to differentiate.

Elias Zerhouni, Director of the NIH, has made sure that the NIH has done its part to promote research using the approved cell lines (26). Special training grants for new hESC investigators have been created; supplements to existing research grants have been offered as lures; and many different calls for special grants (requests for applications and requests for proposals) have been issued. The formation of multidisciplinary teams has been encouraged, and research infrastructure grants in support of hESC-based studies have been proposed. hESC-related conferences have been supported, and an 


\section{Remembering recombinant DNA}

In 1975, 140 representatives of the academic community, mostly biologists, but also a few physicians, lawyers, and reporters, participated in the International Congress on Recombinant DNA Molecules at a conference center in Asilomar, California. They gathered to grapple with an issue that had suddenly come up: the safety of research involving recombinant DNA. Ethical considerations were put aside to focus on biological hazards. The concern was that this new technology might end up creating new and dangerous organisms that could escape from the lab and threaten the public's health. This meeting, often referred to as a landmark of social responsibility and self-governance by scientists, called for a voluntary moratorium on certain types of DNA experiments until the hazards could be evaluated. After much debate, participants agreed on a set of safety guidelines involving the use of disabled bacteria, which are unable to survive outside the lab. This allowed research to proceed and Congress to back off from imposing restrictions.

excellent hESC web site - the official NIH resource for stem cell research - has been created (26).

Whether it is 5,21 , or 62 , the number of available hESC lines is simply not sufficient to provide for the genetic diversity among the recipient population. In developing a new medicine, one would not stop with the first chemical that produced an effect. Efficacy must be optimized and safety must be taken into account.

Creation of new cell lines from human embryos can proceed thanks to support from nongovernment sources. Recently 17 new hESC lines were derived with private funds (27), and more are sure to follow. However, in the long run, the talent represented by the community of scientists supported by the NIH and other federal agencies will be needed for this field to move forward.

Currently in the House of Representatives a bill introduced by D. Weldon (R-FL) and B. Stupak (D-MI) and in the Senate a bill introduced by S. Brownback (R-KS) and M. Landrieu (R-LA) would outlaw the formation of human embryos by SCNT in the private sector as well as by researchers receiving federal funds. This extraordinary legislation would criminalize scientific research, making it punishable by a $\$ 1$ million fine and 10 years in prison. Effects of this chilling attack on the scientific process extend beyond $\mathrm{hESC}$ research. It casts a pall over all science. It indicates a widening gulf between those in public office and the scientific community - a reversal of the coming together of political and scientific minds over the stem cell debate that we are observing in other nations.

\section{Ethical issues}

When does life begin? The answer to this question has enormous consequences for the future study of hESCs. Defining life as the moment of conception is certainly a convenient starting point, but this relies on an assumption about the value of a potential life. In this argument, value is placed on function (potential for future development) rather than structure (current state of development). This starting point, conception, is also promoted by many of those who rely on revealed Scripture. For those holding such beliefs, research on stem cells and the destruction of human blastocysts are simply unacceptable.
To many, implantation of the blastocyst in the uterine wall is the best landmark for the definition of life. Indeed, this is the first stage at which the individual is defined (e.g., the blastula is past the stage in which it can split to form twins). This is the point described in Subpart B of 45CFR46 as the first stage covered by human protections regulations. This is also the last developmental stage accepted in the United Kingdom and in many other countries throughout the world. For research on human embryos, gastrulation is another strong candidate, as it is reasonable to consider the phase in which the nervous system is formed and the possibility of sensation first exists as the beginning of human life.

One of the most dangerous trends in this debate is that of offering religious opinions cloaked in the language and veneer of science (e.g., using systems theory to justify the belief that life begins at conception). We have emphasized differences between embryonic and adult stem cells because many in the public and in Congress have claimed, arbitrarily, that the two sources are identical. Richard Dorflinger, Deputy Director of the Secretariat of the pro-life activities of the US Conference of Catholic Bishops, has claimed that adult stem cells hold more promise than embryonic stem cells and that research on embryonic stem cells is therefore unnecessary. The passion behind Dorflinger's statement is laudable, but it must be recognized that it is based on religious conviction, not on scientific induction or verified data.

Several commissions have explored the difficult ethical issues surrounding the definition of the beginning of life, including the National Bioethics Advisory Commission (28), the National Academy of Sciences Advisory Committee, and most recently, the President's Council on Bioethics $(29,30)$. Although each of these committees condemns research on reproductive cloning, research on SCNT has been upheld even by the President's Council on Bioethics, widely considered to be the most conservative group of the three. While the leader of the President's Council, Leon Kass, is opposed to the creation of embryos by SCNT for research purposes, the committee did not vote to ban SCNT research; rather they called for a four-year moratorium. At the time of the vote, the President's Council on Bioethics contained 17 members; 6 were scientists but only 3 were involved in the fields of cell biology or molecular biology. There were dissenting opinions, but the moratorium carried the day. If one thinks of the time it takes to restart a program once it is dismantled, a four-year moratorium might well turn into a six-year hiatus. Careers would be difficult to maintain, and our best young scientists would probably enter different fields. A similar moratorium initiated at the Asilomar Conference in the 1970s threatened the development of recombinant DNA technology (see Remembering recombinant DNA). In retrospect, a prolonged moratorium would have changed the course of science and industry in this country. In like manner, a prolonged moratorium on SCNT research would be a major setback for individuals interested in maintaining our international preeminence in cell biology and biotechnology and might lead to a brain drain from the US to countries more supportive of this line of research.

Those opposed to research on embryos are concerned that we are on a slippery slope, facing a creeping moral degradation fostered by unbridled biotechnology (30). If we agree to destroy an organism that has the potential to develop into a human being, it may be easy to move on to other destructive acts. This zeal poses the danger of depriving millions who suffer from degenerative disorders of the hope and benefits that might derive from stem cell-based research.

There is no absolute right answer to the debate regarding the dissociation of blastocysts to produce more hESC lines. Here we 
present several considerations that convince us of the ethical validity of using embryos up until the 14th day after fertilization.

Up to embryonic day 14 , the blastocyst has no central nervous system and, in our view, cannot be considered sensate. We now remove organs from patients who have been declared brain dead but who are still alive in some sense (e.g., they are warm, breathing, making urine). The use of these organs has saved many lives. We view these two hundred-cell embryos as cell donors certainly at the same moral status or less than these individuals.

The slippery slope argument that the use of blastocysts created by SCNT will lead to reproductive cloning is not compelling. With appropriate federal regulations and oversight, such as the HatchFeinstein Bill, introduced in the Senate by Orrin Hatch (R-UT) and Dianne Feinstein (D-CA), which seeks to prohibit human reproductive cloning while preserving the use of blastocysts to enhance stem cell research, the scientific community can proceed in an orderly fashion. The UK is now succeeding in this vein under the watchful eye of its Human Fertilisation and Embryology Authority, a nongovernmental body that regulates and inspects all UK clinics providing IVF, donor insemination, and embryo storage while also licensing and monitoring all human embryo research conducted in the UK. The guidepost - implantation into a uterus - is an unambiguous barrier.

The need for hESC research is extraordinary. We are on the doorstep of a new type of restorative therapy that goes beyond treating disease symptoms. Disorders in which the lesions are focal will be the first to undergo stem cell therapy. Replacing $\beta$ cells in the pancreas, motor neurons in the spinal cord, and dopaminergic cells in the basal ganglia are the most obvious examples. We must weigh the obligations of the moral imperative to help suffering individuals against the inherent value of preimplantation blastocysts.

We have many examples in history where attempts to outlaw fields of study have led to terrible and terrifying consequences (from Galileo to Lysenko). Conversely, many technological breakthroughs now highly valued by both the scientific and lay com- munities, such as IVF or heart transplants, were once thought to be too dangerous or were seen as "playing God".

Finally, this effort should go forward because we simply will not know the answers unless we do the research. The desire to know is absolutely intrinsic to humans and has a survival value as well as a moral one.

\section{Conclusion}

Arguments are often made that hESCs have not cured a single disease. Of course not. Research is hampered by current regulations, and it is difficult to succeed with one hand tied behind one's back. As in all great scientific advances, it takes time and a great deal of money to translate fundamental discoveries into clinically useful treatments.

Scientific advances over the last decade have been extraordinary, but the process of discovery is a fragile one. Each advance raises new questions with new ramifications. It will take all of us - scientists, physicians, health care workers, and patient advocates - a certain amount of effort and courage in the face of contrary views to justify public trust and, thereby, enhance funding for basic research and for applied research.

We can be certain that without research, including federally funded research, we will remain in our current state of ignorance. The public must be kept informed about what the research community is doing. We hope that our great universities and research centers remain at the forefront of this effort.

\section{Acknowledgments}

We thank Ross Frommer and Joyce Plaza for careful reading and thoughtful comments on this manuscript.

Address correspondence to: Gerald D. Fischbach, Faculty of Medicine, Columbia University College of Physicians and Surgeons, P\&S 2-401, 630 West 168th Street, New York, New York 10032, USA. Phone: (212) 305-2752; Fax: (212) 305-3617; E-mail: gdf@columbia.edu.
1. Evers, B.M., Weissman, I.L., Flake, A.W., Tabar, V., and Weisel, R.D. 2003. Stem cells in clinical practice. J. Am. Coll. Surg. 197:458-478.

2. Raff, M. 2003. Adult stem cell plasticity: fact or artifact? Annu. Rev. Cell Dev. Biol. 19:1-22.

3. Wagers, A.J., and Weissman, I.L. 2004. Plasticity of adult stem cells. Cell. 116:639-648.

4. Thomson, J.A., et al. 1998. Embryonic stem cell lines derived from human blastocysts. Science. 282:1145-1147.

5. Wichterle, H., Lieberam, I., Porter, J.A., and Jessell, T.M. 2002. Directed differentiation of embryonic stem cells into motor neurons. Cell. 110:385-397.

6. Isacson, O. 2004. Problems and solutions for circuits and synapses in Parkinson's disease. Neuron. 43:165-168.

7. Kim, J.H., et al. 2002. Dopamine neurons derived from embryonic stem cells function in an animal model of Parkinson's disease. Nature. 418:50-56.

8. Ricordi, C., and Strom, T.B. 2004. Clinical islet transplantation: advances and immunological challenges. Nat. Rev. Immunol. 4:259-268.

9. Liu, E.H., and Herold, K.C. 2000. Transplantation of the islets of Langerhans: new hope for treatment of type 1 diabetes mellitus. Trends Endocrinol. Metab. 11:379-382.

10. Shapiro, A.M., et al. 2000. Islet transplantation in seven patients with type 1 diabetes mellitus using a glucocorticoid-free immunosuppressive regimen. N. Engl. J. Med. 343:230-238.
11. Freed, C.R., et al. 2001. Transplantation of embryonic dopamine neurons for severe Parkinson's disease. N. Engl. J. Med. 344:710-719.

12. Hochedlinger, K., et al. 2004. Nuclear transplantation, embryonic stem cells and the potential for cell therapy. Hematol. J. 5(Suppl. 3):S114-S117.

13. Hwang, W.S., et al. 2004. Evidence of a pluripotent human embryonic stem cell line derived from a cloned blastocyst. Science. 303:1669-1674.

14. Normile, D. 2004. Research ethics. South Korean cloning team denies improprieties. Science. 304:945.

15. Vogel, G. 2004. Human cloning. Scientists take step toward therapeutic cloning. Science. 303:937-939.

16. Campbell, K.H., McWhir, J., Ritchie, W.A., and Wilmut, I. 1996. Sheep cloned by nuclear transfer from a cultured cell line. Nature. 380:64-66.

17. Wilmut, I. 1999. Dolly's false legacy. Time.74:76-77.

18. Wilmut, I. 2003. Dolly - her life and legacy. Cloning Stem Cells. 5:99-100.

19. Jaenisch, R. and Wilmut, I. 2001. Developmental biology. Don't clone humans! Science. 291:2552.

20. Rideout, W.M., Eggan, K., and Jaenisch, R. 2001. Nuclear cloning and epigenetic reprogramming of the genome. Science. 293:1093-1097.

21. Wilmut, I., et al. 2002. Somatic cell nuclear transfer. Nature. 419:583-586.

22. Jaenisch, R. and Bird, A. 2003. Epigenetic regulation of gene expression: how the genome integrates intrinsic and environmental signals [review]. Nat Genet. 33(Suppl.):245-254.

23. Eggan, K., et al. 2004. Mice cloned from olfactory sensory neurons. Nature. 428:44-49.

24. The National Commission for the Protection of Human Subjects of Biomedical and Behavioral Research. 1978. The Belmont report: ethical principles and guidelines for the protection of human subjects of research. The National Commission. Bethesda, Maryland, USA.

25. National Institutes of Health. 2004. Stem cell information. Research topics. http://stemcells.nih. gov/research.

26. Zerhouni, E. 2003. Stem cell programs. Science. 300:911-912.

27. Cowan, C.A., et al. 2004. Derivation of embryonic stem-cell lines from human blastocysts. N. Engl. J. Med. 350:1353-1356.

28. National Bioethics Advisory Commission. 1999. Ethical issues in human stem cell research. National Bioethics Advisory Commission. Rockville, Maryland, USA.

29. President's Council on Bioethics. 2002. Human cloning and human dignity: an ethical inquiry. The President's Council on Bioethics. Washington, DC, USA.

30. President's Council on Bioethics. 2003. Beyond therapy: biotechnology and the pursuit of happiness. A report of the President's Council on Bioethics. 1st edition. ReganBooks. New York, New York, USA. 328 pp.

31. Hochedlinger, K., and Jaenisch, R., 2003. Nuclear transplantation, embryonic stem cells, and the potential for cell therapy. N. Engl. J. Med. 349:275-286. 